\title{
The nurse
}

\author{
J. Stevenson \\ S.R.N.
}

\author{
St Bartholomew's Hospital, London
}

\begin{abstract}
Summary
Nurses are usually taught approved names for drugs, but this leads to confusion with combination products. Problems in drug administration arise when one name is marked on the bottle of tablets and the other name on the prescription sheet. From the nurses' point of view, standardization is essential.
\end{abstract}

Florence Nightingale once said that hospitals 'should do the sick no harm' and as nurses, we are very much concerned with making sure that the patients in our care do not come to any harm. We are 'go-betweens', responsible for ensuring that our patients receive the treatment intended by their physicians and surgeons. It is impossible to say which of the many nursing procedures are the most important, but administration of drugs must come very high on the list. It is almost always nurses who give patients their drugs, the exceptions being the few occasions when a drug must be given by medical staff, intravenous and intrathecal injections being examples.

There are so many things to learn about drugs, what they are, why they are given, the various forms of administration and so on. There are tablets, capsules, lozenges, powders, granules, syrups, injections, inhalations and intravenous solutious, They may be given once, twice, three and four times a day, 3-, 4-, 6-, 8- and 12-hourly, all requiring careful checking so that the right drug is given to the right patient at the right time. It is hardly surprising that we are sometimes a little confused by the administration of drugs, but at present it is not so much by the time and method of administration, but by the way they are prescribed.

Since the use of the General Nursing Council's 1969 syllabus of training for State Registration, nurses no longer have a $1 \mathrm{hr}$ State practical examination, but a four-part examination, which must be completed during the second and third years of their training. Part B of this examination tests the nurse's ability to perform a drug round. The days when drug administration was the sole responsibility of trained staff have disappeared, not only because there seems to be a shortage of qualified nurses, but also because student nurses have to do drug rounds, under supervision, to become competent for their examination.

At St Bartholomew's Hospital nurses are taught approved names because this is a Ministry recommendation which has been accepted by the Hospital's Medical Council and is hospital policy. The hospital's medical students are also taught approved names and medical staff are encouraged to use approved names whenever possible, with certain suggested exceptions when it is preferable that a trade name be used, for example Burroughs Wellcome Lanoxin. In theory this is very straightforward, but in practice, it does not quite work out that way. I presume that medical staff use names they have been taught during their training, which is probably why we find a mixture of trade and approved names on prescription sheets. Also, it is fairly reasonable to suppose that doctors use names with which they are more familiar. One may well be taught to prescribe dextropropoxyphene $32.5 \mathrm{mg}$ and paracetamol $325 \mathrm{mg}$ but Distalgesic is a much more familar name, and far more easily written.

It is also important from our point of view to consider the way drugs are dispensed, because this is where a lot of our queries at St Bartholomew's arise. Hospital policy states that approved names should be marked on bottles and boxes, and the pharmacy does this regardless of the name written on the prescription sheet. If, therefore, Lasix is prescribed, the bottle is marked frusemide. This is a problem which causes us considerable headache, especially if the drug is not a familiar one. Just as an example, not long ago, on an extremely busy morning, a senior student nurse, making a valiant attempt to do a drug round undisturbed, brought me a bottle of tablets marked pentaerithrytyl tetranitrate $10 \mathrm{mg}$. The prescription said Peritrate $10 \mathrm{mg}$ and the nurse quite correctly wanted to check that she was giving the right drug. When this happens, two of us look up the drug, check both names, and write the approved name on the prescription sheet with the trade name prescribed. Each time this happens, 
the nurse has to leave her drug trolley in charge of another nurse and check the prescription. I feel that checking these drugs is a necessary waste of time, necessary because we must be certain that we are giving the right drug, and a waste of time, because if we used one name or the other all the time, the situation would not arise, and we would save precious minutes of which we have few to spare.

As if life is not complicated enough, we also know that one drug can have more than one trade name when it is made by different firms. According to our very well thumbed copy of 'MIMS', Phenylbutazone can be Benzone, Butazolidine, Butazone, Butaphen and Flexazone. So it is quite possible, although unlikely one hopes, to have five patients on one ward taking Phenylbutazone, each prescribed with a different trade name.

We are also occasionally given more than one trade name preparation of the same stock drug, usually injections because we are given the boxes in which they are supplied. I recently had two boxes of Metaclopramide $10 \mathrm{mg}$ for injection in the drug cupboard, one called Maxalon, the other Primperan. Someone had written Maxalon on the box of Primperan!
I do not really feel qualified to provide the solution and I do not wish to make any guesses. I feel, how-.ever, that it is now an absolute necessity for us to $\Rightarrow$ use one name or the other for prescribing, because? until we do the confusion that exists now will con-o

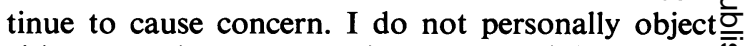
either to trade or approved names. Possibly I favour $\frac{\bar{\rho}}{\bar{S}}$ approved names, if only because they are the names $\stackrel{\mathbb{}}{\varrho}$ I have been taught and I would have to familiarizes myself with trade names if they were chosen.

From the nurse's point of view, I do not think the $\overrightarrow{-}$ name of the drug prescribed really matters. What $\vec{\omega}$ does matter is the fact that our methods of pre- $\odot$ scribing and dispensing must be standardized, and: there are three points which I think should be con-3. sidered. Firstly, the prescribed name must be the i same as the name marked on the bottle by the pharmacy. Secondly, drugs such as Distalgesic, ${ }^{\circ}$ which are a combination of more than one pre- -0 paration must be identified by a single name, and 0 thirdly, if more than one formulation is available on? the ward as a stock drug, the formulation must be identified by the prescriber. If this can be done, these $\frac{\mathbb{}}{O}$ problems of drug administration which concern nurses so much, will I hope no longer exist. 